\title{
Comparing the Atmospheric Compositions of All Planets and Giant Moons in Solar System
}

\section{Rauf KM, Hossieni $\mathbf{H}^{*}$, Majeed D and Ibrahim $\mathbf{R}$}

Department of Physics, School of Science, University of Sulaimani, Kurdistan, Iraq

*Corresponding author: Hossieni H, Department of Physics, School of Science, University of Sulaimani, Kurdistan, Iraq, Tel: +964 770 1991949; E-mail: hossien.hossieni@univsul.edu.iq

Rec date: July 13, 2015; Acc date: July 27, 2015; Pub date: July 30, 2015

Copyright: ( 2015 Rauf KM, et al. This is an open-access article distributed under the terms of the Creative Commons Attribution License, which permits unrestricted use, distribution, and reproduction in any medium, provided the original author and source are credited.

\begin{abstract}
In this research we have studied the atmosphere in both giant gaseous and soil planets in solar system. The ratio of gases in atmosphere of the planets are compared and determined which of the elements has the maximum value in the planets. It is also shown that the composition of the majority of giant planets is Nitrogen and Hydrogen because they are massive and cold.
\end{abstract}

Keywords: Planet; Solar systems; Giant gaseous; Atmosphere

\section{Introduction}

Our Solar system is a star system including Sun, eight planets (Earth, Mercury, Venus, Mars, Jupiter, Saturn, Uranus, Neptune) and five dwarf planet (Ceres, Pluto, Haumea, Makemake, Eris). First four planets, Earth, Mercury, Venus and Mars are soil planets. They are also called the inner planets, because their orbits are nearby the Sun but other planets are giant gaseous planets and they are classified as the outer planets. In addition to the planets, solar system contains moons, asteroids, comets, meteors and some particular region as asteroids belt, Kuiper belt, scattered disk and Oort cloud. Moreover, there is an ethereal matter in the planetary space that made of natural Hydrogen, plasma gaseous, cosmic rays and dust particles [1].

Besides the planets, giant moons of the solar system hold atmosphere. Composition of the planets and the moons are widely different. Atmosphere of mercury consist of those atomic and subatomic particles which stemming from the Sun [2]. On the other hand, Earth's atmosphere is typically dense and consists of a wide range of different gases. The ratio of oxygen gas in celestial bodies' atmosphere is very low except Earth's atmosphere because oxygen is very active gas and interacts with other elements. Moreover, the ratio of hot oxygen in higher levels of the atmospheres of Mars and Venus is considerable [3].

The force that holds atmosphere around the planets is gravity force. A massive planet means its atmosphere is thick and the elements with high escape velocity like Hydrogen and Helium elements remain in its atmosphere while the majority of gases in the atmosphere of small celestial bodies are massive gases like $\mathrm{CO}_{2}$ and other massive chemical components [4]. In this study the atmosphere of the planets and the moons in Solar system has been studied and a comparison has been made in compositions of the atmospheres of the planets and moons.

\section{Atmosphere of the Bodies in Solar System}

In solid matter, atoms and molecules are kept together hardly while in gases the situation is different because the connections between the molecules are very weak and they can move freely. Since the gravitational force keeps the molecules around the planets therefore the smaller planet means its gravitational force is weaker and in the result the density of the gases is low. For example moon, Mercury and other small objects in solar system cannot hold gases around themselves because of their low gravity. On the other hand, if the planet is cold it can hold gases. This is the reason why Mars has a tiny atmosphere but mercury does not. The density of Mars's atmosphere is about 1/100 of Earth's atmosphere, but of course with different gases. Existing Oxygen gas in an atmosphere of a planet is bizarre because this gas is so active and disappears in very short time. Earth's atmosphere holds oxygen because of the plants on the surface of our planet [5].

In the other hand, the giant gaseous planets can hold Hydrogen and Nitrogen and they have remained huge [6] while moons of these planets are small and cannot have the atmosphere with an exception of Titan. Titan is the large moon of Saturn, it is big and cold, and it has held its atmosphere where Nitrogen is the most of its composition [7].

Beside gravitational force, another reason for holding gases is physical conditions. The speed of small atoms or molecules in a certain temperature is very high and gravitational force cannot hold them such as Venus. There are Oxygen and Nitrogen in the atmosphere of Venus. Although it has the atmosphere that is comparable to the Earth's size, but it is nearby the Sun thus it is very hot and all chemical carbonate compositions decays. Therefore the Venus's atmosphere is filled by $\mathrm{CO}_{2}$ and it is denser than the Earth's atmosphere. This is the answer of why Venus is hotter than Mercury [8].

\section{Distribution of Gases in the Atmosphere of the Planets}

Figure 1 shows the amount of hydrogen gas in the atmosphere of each of the planets set in tables. Probable source for existing hydrogen in the atmosphere of the planets is the solar wind. It can be noticed that the atmosphere of Saturn contains the maximum amount of hydrogen than the other planets by the amount of $88 \%$ of total amount of its atmosphere while Jupiter's atmosphere covered $86.4 \%$ of its atmosphere with hydrogen. $82.5 \%$ of Uranus's atmosphere is hydrogen and $80 \%$ for Neptune's atmosphere while in Mercury's atmosphere is only $22 \%$ and Earth's atmosphere has the lowest value among the planets which is $6 \times 10-5 \%$ of its atmosphere. 


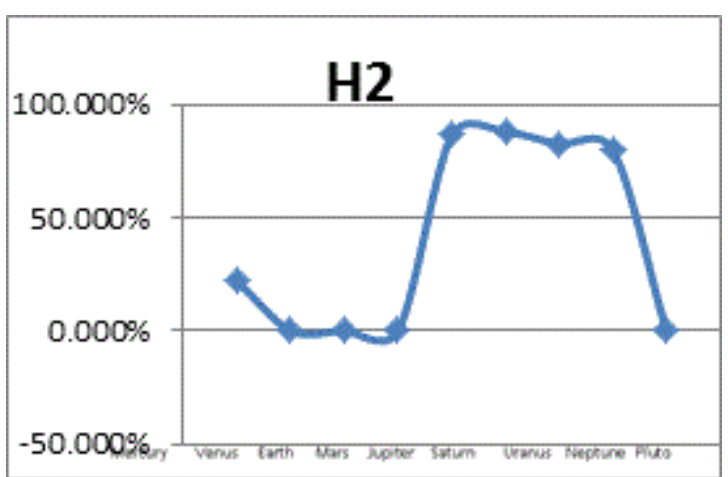

Figure 1: the abundance of Hydrogen gas in atmosphere of the planets. It is clear that this abundance has the maximum value in giant planets.

Similarly Figure 2 shows the amount of helium gas in the atmosphere of each of the planets set in tables. The atmosphere of Neptune contains the maximum amount of helium than the other planets by the amount of $19 \%$ of total amount of its atmosphere while $15 \%$ of Uranus's atmosphere is helium and $13.6 \%$ of Jupiter's atmosphere and $12 \%$ for Saturn's atmosphere. Earth has very low helium in its atmosphere which is only $5.24 \times 10-4 \%$ of the total amount of the gases and Venus's atmosphere has (12 ppm) helium in its atmosphere.

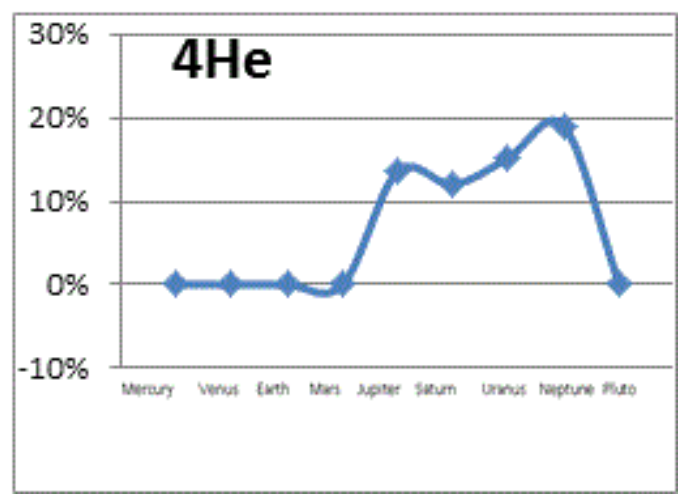

Figure 2: the abundance of Helium gas in atmosphere of planets. Similar to Hydrogen rate the Helium in giant gas planets is large and in Neptune is maximum

Moreover, Figure 3 shows the amount of Methane gas in the atmosphere of each of the planets. The atmosphere of dwarf planet such as Pluto contains the maximum amount of Methane than the other planets by the amount of $2.5 \%$ of total amount of its atmosphere. Uranus's atmosphere has Methane of about $2.3 \%$ of its atmosphere and $2 \%$ for Neptune's atmosphere.

Other planets have less methane in their atmosphere such as Saturn's atmosphere which contains $0.0047 \%$ methane and $0.00181 \%$ of Jupiter's atmosphere is covered by Methane while Earth's atmosphere has $0.00018 \%$ Methane of the total amount of the gases and 10-250 ppb for Mars.

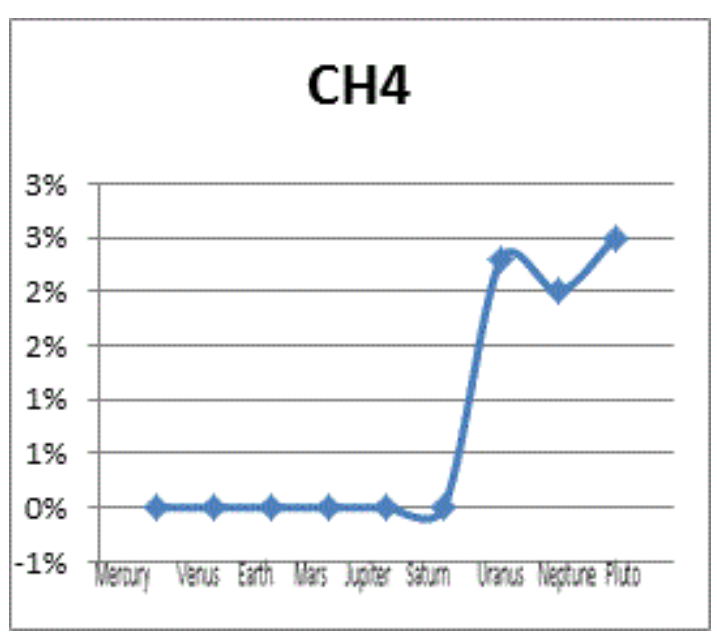

Figure 3: the abundance of Methane gas in atmosphere of planets. It can be seen that far planets have maximum amount of methane.

Furthermore, Figure 4 shows the amount of Ammonia gas in the atmosphere of each of the planets. The atmosphere of Jupiter contains the maximum amount of Ammonia than the other planets by the amount of $0.0006 \%$ while $0.00016 \%$ of Saturn's atmosphere covered by Ammonia and only $<100 \mathrm{ppb}$ of Uranus's atmosphere is Ammonia and $<600 \mathrm{ppb}$ for Neptune's atmosphere.

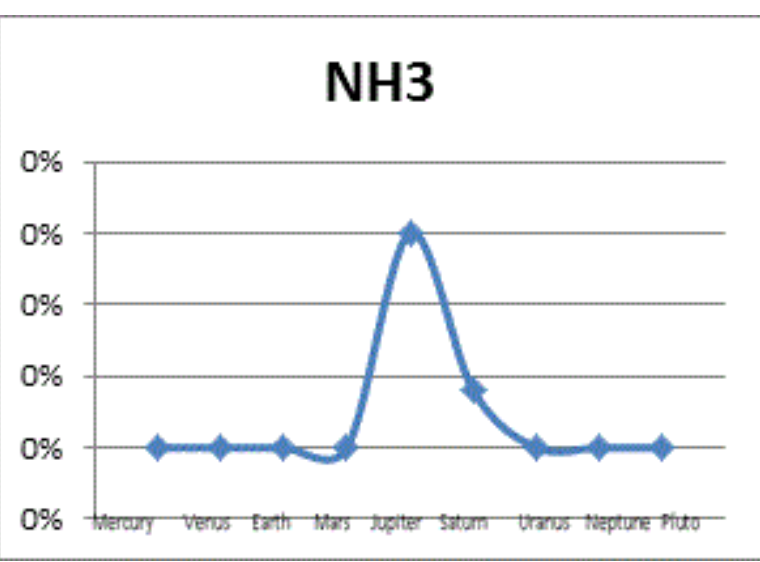

Figure 4: the abundance of Ammonia gas in solar system, maxim ratio of the gas is in Jupiter

Additionally, Figure 5 indicates the amount of $\mathrm{H}_{2} \mathrm{O}$ in the atmosphere of each of the planets in solar system. Certainly the atmosphere of Earth contains the maximum amount of $\mathrm{H}_{2} \mathrm{O}$ than the other planets by the amount of $0.0001 \%$ of total amount of its atmosphere. Jupiter's atmosphere has only 520 ppm $\mathrm{H}_{2} \mathrm{O}$ and $<100$ ppm of Mars's atmosphere is $\mathrm{H}_{2} \mathrm{O}$ while Venus's atmosphere contains $2 \mathrm{ppm} \mathrm{H}_{2} \mathrm{O}$ and 2-20 ppb for Saturn's atmosphere.

In Table 1a-1c we summarized all chemical components and elements in the atmosphere of the planets in solar system. These components started with hydrogen and end with HF [9]. 
Citation: Rauf KM, Hossieni H, Majeed D, Ibrahim R (2015) Comparing the Atmospheric Compositions of All Planets and Giant Moons in Solar

(a)

\begin{tabular}{|c|c|c|c|c|c|c|c|c|c|c|c|}
\hline Planet & $\mathbf{H}_{2}$ & $4 \mathrm{He}$ & $\mathrm{CH}_{4}$ & $\mathbf{N H}_{3}$ & $\mathrm{H}_{2} \mathrm{O}$ & $\mathrm{H}_{2} \mathrm{~S}$ & HD & $13 \mathrm{CH} 4$ & $\mathrm{C} 2 \mathrm{H} 6$ & PH3 & $\mathrm{CH} 3 \mathrm{D}$ \\
\hline Mercury & $22.000 \%$ & $0 \%$ & $0 \%$ & $0 \%$ & $0 \%$ & $0 \%$ & $0 \%$ & $0 \%$ & $0 \%$ & $0 \%$ & $0 \%$ \\
\hline Venus & $0 \%$ & $12 \mathrm{ppm}$ & $0 \%$ & $0 \%$ & $2 \mathrm{ppm}$ & $0 \%$ & $0 \%$ & $0 \%$ & $0 \%$ & $0 \%$ & $0 \%$ \\
\hline Earth & $0.000060 \%$ & $\begin{array}{l}0.000524 \\
\%\end{array}$ & $\begin{array}{l}0.00018 \\
0 \%\end{array}$ & $0 \%$ & $0.000100 \%$ & $0 \%$ & $0 \%$ & $0 \%$ & $0 \%$ & $0 \%$ & $0 \%$ \\
\hline Mars & $0 \%$ & $0 \%$ & $\begin{array}{l}10-250 \\
\mathrm{ppb}\end{array}$ & $0 \%$ & $<100$ ppm & $0 \%$ & $0 \%$ & $0 \%$ & $0 \%$ & $0 \%$ & $0 \%$ \\
\hline Jupiter & $86.400 \%$ & $13.600 \%$ & $\begin{array}{l}0.00181 \\
0 \%\end{array}$ & $\begin{array}{l}0.000600 \\
\%\end{array}$ & 520 ppm & 67 ppm & $\begin{array}{l}45 \pm 12 \\
\mathrm{ppm}\end{array}$ & $\begin{array}{l}19 \pm 1 \\
\mathrm{ppm}\end{array}$ & $\begin{array}{l}5.8 \pm 1.5 \\
\mathrm{ppm}\end{array}$ & $\begin{array}{l}1.1 \pm 0.4 \\
\mathrm{ppm}\end{array}$ & $\begin{array}{l}0.2 \pm 0.04 \\
\mathrm{ppm}\end{array}$ \\
\hline Saturn & $88.000 \%$ & $12.000 \%$ & $\begin{array}{l}0.00470 \\
0 \%\end{array}$ & $\begin{array}{l}0.000160 \\
\%\end{array}$ & $2-20 \mathrm{ppb}$ & $<0.4 \mathrm{ppm}$ & $\begin{array}{l}110 \pm 58 \\
\mathrm{ppm}\end{array}$ & $\begin{array}{l}51 \pm 2 \\
\mathrm{ppm}\end{array}$ & $\begin{array}{l}7.0 \pm 1.5 \\
\mathrm{ppm}\end{array}$ & $\begin{array}{l}4.5 \pm 1.4 \\
\mathrm{ppm}\end{array}$ & $\begin{array}{l}0.3 \pm 0.02 \\
\mathrm{ppm}\end{array}$ \\
\hline Uranus & $82.500 \%$ & $15.200 \%$ & $2.300 \%$ & $<100 \mathrm{ppb}$ & $0 \%$ & $<0.8 \mathrm{ppm}$ & 148 ppm & $0 \%$ & $0 \%$ & $0 \%$ & $8.3 \mathrm{ppm}$ \\
\hline Neptune & $80.000 \%$ & $19.000 \%$ & $2.000 \%$ & $<600 \mathrm{ppb}$ & $0 \%$ & $<3 \mathrm{ppm}$ & 192 ppm & $0 \%$ & $0 \%$ & $0 \%$ & $12 \mathrm{ppm}$ \\
\hline Pluto & $0 \%$ & $0 \%$ & $2.500 \%$ & $0 \%$ & $0 \%$ & $0.00 \%$ & $0 \%$ & $0 \%$ & $0 \%$ & $0 \%$ & $0 \%$ \\
\hline
\end{tabular}

(b)

\begin{tabular}{|c|c|c|c|c|c|c|c|c|c|c|c|}
\hline Planet & $\mathrm{C}_{2} \mathrm{H}_{2}$ & $\mathrm{HCN}$ & $\mathrm{HC}_{3} \mathrm{~N}$ & $\mathrm{C}_{2} \mathrm{H}_{4}$ & $\mathrm{CO}_{2}$ & $\mathrm{C}_{2} \mathrm{H}_{6}$ & $\mathrm{CH}_{3} \mathrm{C}_{2} \mathrm{H}$ & $\mathrm{Co}$ & $\mathrm{CH}_{3} \mathrm{CN}$ & $\mathrm{GeH}_{4}$ & $\mathrm{C}_{4} \mathrm{H}_{2}$ \\
\hline Mercury & $0 \%$ & $0 \%$ & $0 \%$ & $0 \%$ & $0 \%$ & $0 \%$ & $0 \%$ & $0 \%$ & $0 \%$ & $0 \%$ & $0 \%$ \\
\hline Venus & $0 \%$ & $0 \%$ & $0 \%$ & $0 \%$ & $96.500 \%$ & $0 \%$ & $17 \mathrm{ppm}$ & $0 \%$ & $0 \%$ & $0 \%$ & $0 \%$ \\
\hline Earth & $0 \%$ & $0 \%$ & $0 \%$ & $0 \%$ & $0.040000 \%$ & $0 \%$ & $0 \%$ & $0 \%$ & $0 \%$ & $0 \%$ & $0 \%$ \\
\hline Mars & $0 \%$ & $0 \%$ & $0 \%$ & $0 \%$ & $96.000 \%$ & $0 \%$ & $0 \%$ & $0 \%$ & $0 \%$ & $0.055700 \%$ & $0 \%$ \\
\hline Jupiter & $\begin{array}{l}0.11 \pm 0.03 \\
\mathrm{ppm}\end{array}$ & $\begin{array}{l}60 \pm 10 \\
\mathrm{ppb}\end{array}$ & $0 \%$ & $7 \pm 3 \mathrm{ppb}$ & 5-35 ppb & $0 \%$ & $\begin{array}{l}2.5-1+2 \\
\mathrm{ppb}\end{array}$ & $\begin{array}{l}1.6 \pm 0.3 \\
\mathrm{ppb}\end{array}$ & $0 \%$ & $\begin{array}{l}0.70 .4-0.2 \\
\mathrm{ppb}\end{array}$ & $0.3 \pm 0.2 \mathrm{ppb}$ \\
\hline Saturn & $\begin{array}{l}0.3 \pm 0.1 \\
\mathrm{ppm}\end{array}$ & $<4 \mathrm{ppb}$ & $0 \%$ & $0.2 \mathrm{ppb}$ & $0.3 \mathrm{ppb}$ & $0 \%$ & $0.6 \mathrm{ppb}$ & $\begin{array}{l}1.4 \pm 0.7 \\
\mathrm{ppb}\end{array}$ & $0 \%$ & $\begin{array}{l}0.4 \\
\mathrm{ppb}\end{array}$ & $0.09 \pm p p b$ \\
\hline Uranus & $10 \mathrm{ppb}$ & $<15 \mathrm{ppb}$ & $<0.8 \mathrm{ppb}$ & $0 \%$ & $40 \pm 5 p p t$ & $10 \pm 1 \mathrm{ppb}$ & $\begin{array}{l}0.25 \pm 0.3 \\
\mathrm{ppb}\end{array}$ & $<40 \mathrm{ppb}$ & $0 \%$ & $0 \%$ & $\begin{array}{l}0.16 \pm 0.02 \\
\mathrm{ppb}\end{array}$ \\
\hline Neptune & $60 \mathrm{ppb}$ & $\begin{array}{l}0.3 \pm 0.15 \\
\mathrm{ppb}\end{array}$ & $<0.4 \mathrm{ppb}$ & $0 \%$ & $0 \%$ & $\begin{array}{l}1.5+25-0.5 \\
\mathrm{ppm}\end{array}$ & $0 \%$ & $\begin{array}{l}0.65 \quad \pm \\
0.35 \mathrm{ppm}\end{array}$ & $<5 \mathrm{ppb}$ & $0 \%$ & $0 \%$ \\
\hline Pluto & $0 \%$ & $0 \%$ & $0 \%$ & $0 \%$ & $0 \%$ & $0 \%$ & $0 \%$ & $0.500 \%$ & $0 \%$ & $0 \%$ & $0 \%$ \\
\hline
\end{tabular}

(C)

\begin{tabular}{|l|l|l|l|l|l|l|l|l|l|l|l|}
\hline Planet & $\mathbf{A s H 3}$ & $\mathbf{A r}$ & $\mathbf{N}_{2}$ & $\mathbf{N e}$ & $\mathbf{K r}$ & $\mathbf{O}_{2}$ & $\mathbf{N a}$ & $\mathbf{S O}_{2}$ & $\mathbf{H C I}$ & $\mathbf{H F}$ & $\mathbf{O t h e r ~ g a s e s ~}$ \\
\hline Mercury & $0 \%$ & $0 \%$ & $0 \%$ & $0 \%$ & $0 \%$ & $42.000 \%$ & $29.000 \%$ & $0 \%$ & $0 \%$ & $0 \%$ & $7.000 \%$ \\
\hline Venus & $0 \%$ & $70 \mathrm{ppm}$ & $3.500 \%$ & $7 \mathrm{ppm}$ & $0 \%$ & $0 \%$ & $0 \%$ & $150 \mathrm{ppm}$ & $\begin{array}{l}0.1-0.6 \\
\mathrm{ppm}\end{array}$ & $0.001 \mathrm{ppm}$ & $0 \%$ \\
\hline Earth & $0 \%$ & $\begin{array}{l}0.934000 \\
\%\end{array}$ & $78.000 \%$ & 0.001818 & $0.000114 \%$ & $20.946 \%$ & $0 \%$ & $0 \%$ & $0 \%$ & $0 \%$ & $0 \%$ \\
\hline Mars & $0 \%$ & $1.900 \%$ & $1.900 \%$ & $0 \%$ & $0 \%$ & $0.15000 \%$ & $0 \%$ & $0 \%$ & $0 \%$ & $0 \%$ & $0 \%$ \\
\hline Jupiter & $\begin{array}{l}0.22 \pm 0.11 \\
\mathrm{ppb}\end{array}$ & $0 \%$ & $0 \%$ & $0 \%$ & $0 \%$ & $0 \%$ & $0 \%$ & $0 \%$ & $0 \%$ & $0 \%$ & $0 \%$ \\
\hline Saturn & $\begin{array}{l}2.1 \pm 1.3 \\
\mathrm{ppb}\end{array}$ & $0 \%$ & $0 \%$ & $0 \%$ & $0 \%$ & $0 \%$ & $0 \%$ & $0 \%$ & $0 \%$ & $0 \%$ & $0 \%$ \\
\hline Uranus & $0 \%$ & $0 \%$ & $0 \%$ & $0 \%$ & $0 \%$ & $0 \%$ & $0 \%$ & $0 \%$ & $0 \%$ & $0 \%$ & $0 \%$ \\
\hline
\end{tabular}


Citation: Rauf KM, Hossieni H, Majeed D, Ibrahim R (2015) Comparing the Atmospheric Compositions of All Planets and Giant Moons in Solar

\begin{tabular}{|l|l|l|l|l|l|l|l|l|l|l|l|}
\hline Neptune & $0 \%$ & $0 \%$ & $0 \%$ & $0 \%$ & $0 \%$ & $0 \%$ & $0 \%$ & $0 \%$ & $0 \%$ & $0 \%$ & $0 \%$ \\
\hline Pluto & $0 \%$ & $0 \%$ & $97.000 \%$ & $0 \%$ & $0 \%$ & $0 \%$ & $0 \%$ & $0 \%$ & $0 \%$ & $0 \%$ & $0 \%$ \\
\hline
\end{tabular}

Table 1(a-c): All three tables shows that, amount of different gases in the atmosphere of different planets in solar system.

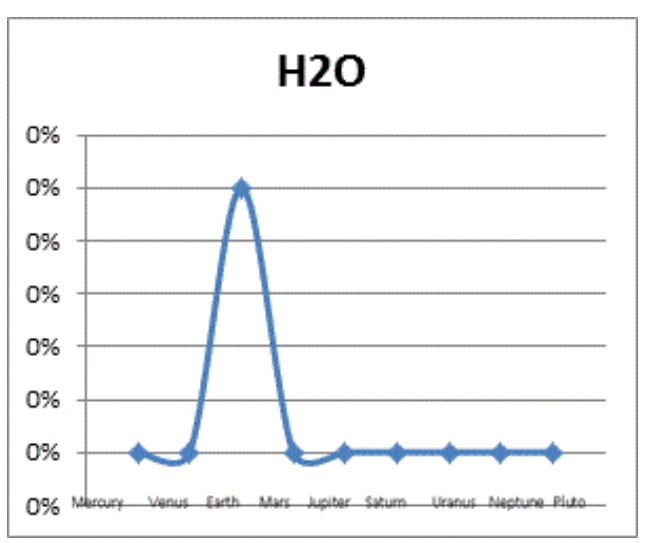

Figure 5: the figure shows the abundance of water gas in solar system, the amount of the water in the Earth's atmosphere is more than other planets.

Figure 6 shows the amount of $\mathrm{CO}_{2}$ in the atmosphere of each of the planets set in the tables. The atmosphere of Venus contains the maximum amount of $\mathrm{CO}_{2}$ than the other planets by the amount of $96.5 \%$ of total amount of its atmosphere and the reason for having such amount of $\mathrm{CO}_{2}$ has been clarified above. And Mars's atmosphere has $96 \% \mathrm{ppm} \mathrm{CO}_{2}$ whereas $0.04 \%$ of Earth's atmosphere is covered by $\mathrm{CO}_{2}$. The amount of $\mathrm{CO}_{2}$ for Jupiter's atmosphere is about $5-35 \mathrm{ppb}$ and for Saturn's atmosphere is $0.3 \mathrm{ppb}$ and this amount is $40 \pm 5 \mathrm{ppt}$ for Neptune's atmosphere.

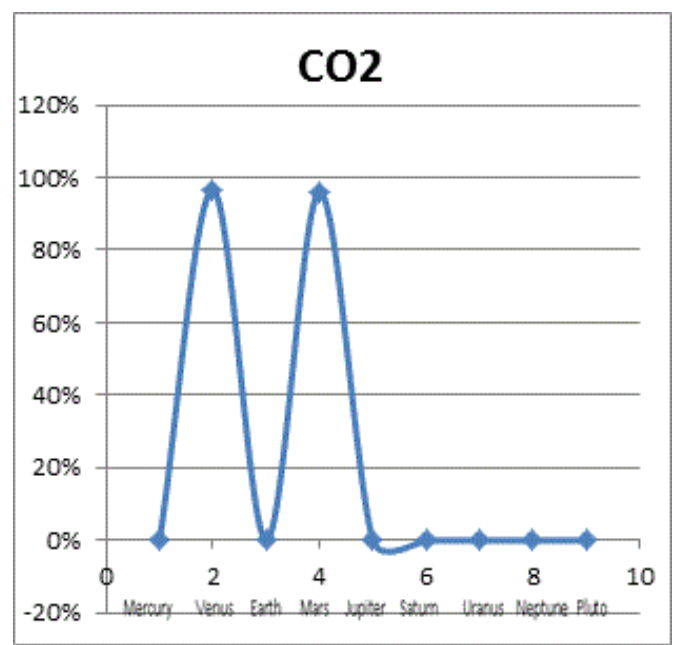

Figure 6: the amount of $\mathrm{CO}_{2}$ in the atmosphere of each of the planets. Maximum amount of this gas is held by Venus and Mars.
Figure 7 shows the amount of N2 in the atmosphere of each of the planets. The atmosphere of Pluto contains the maximum amount of $\mathrm{N} 2$ than the other planets by the amount of $97 \%$ of total amount of its atmosphere while Earth's atmosphere contains 78\% N2. Also 3.5\% of Venus's atmosphere is N2 and 1.9\% for Mars's atmosphere.

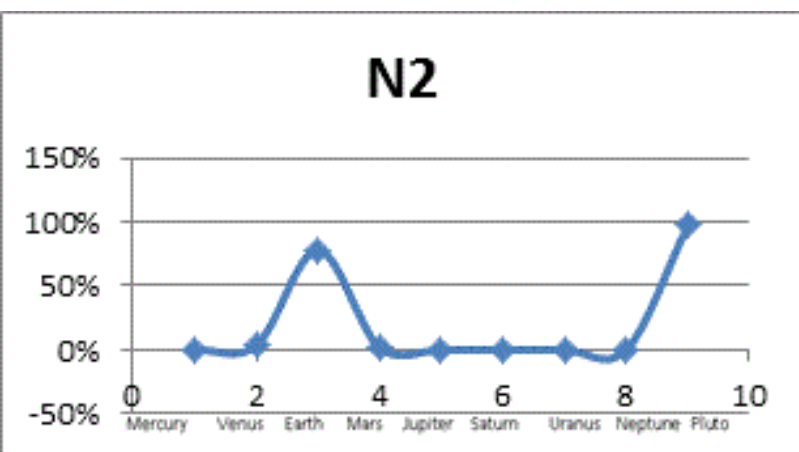

Figure 7: the ratio of nitrogen gas in planet's atmospheres, this ratio has its maximum in Pluto and Earth.

Figure 8 indicates the amount of $\mathrm{O}_{2}$ in the atmosphere of each of the planets set in the tables. The atmosphere of Mercury contains the maximum amount of $\mathrm{O}_{2}$ than the other planets by the amount of $42 \%$ of total amount of its atmosphere while $20.946 \%$ of Earth's atmosphere is covered by $\mathrm{O}_{2}$ and $0.15 \%$ of Mars's atmosphere is $\mathrm{O}_{2}$.

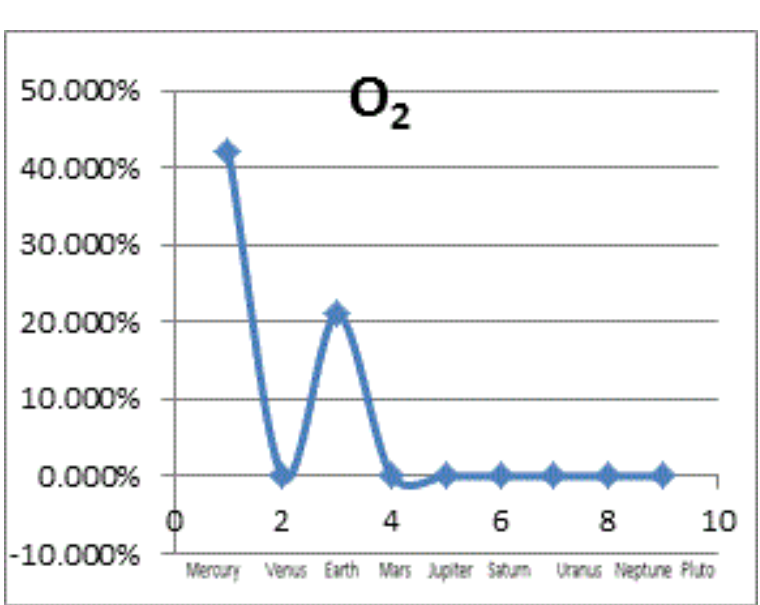

Figure 8: the ratio of oxygen gas in atmosphere of the planets. In compare to other planets Mercury has the highest.

\section{Conclusion}

Our Solar System is hardly a microbe compared with the Universe. This research has studied the atmosphere of the planets of solar system 
Citation: Rauf KM, Hossieni H, Majeed D, Ibrahim R (2015) Comparing the Atmospheric Compositions of All Planets and Giant Moons in Solar System. Astrobiol Outreach 3: 136. doi:10.4172/2332-2519.1000136

Page 5 of 5

that contain eight planets (Mercury, Venus, Earth, Mars, Jupiter, Uranus, Saturn and Neptune). The rate of gases in the atmosphere of the planets change from planet to other that mostly contain of hydrogen $\left(\mathrm{H}_{2}\right)$, oxygen $(\mathrm{O} 2)$ and carbon dioxide $\left(\mathrm{CO}_{2}\right)$. From our graphs it can be noticed that the maximum rate of $4 \mathrm{He}$ appear in Neptune, $\mathrm{H}_{2}$ appear in Saturn, $\mathrm{CH}_{4}$ in Pluto, $\mathrm{NH}_{3}$ in Jupiter, $\mathrm{H}_{2} \mathrm{O}$ in Earth, $\mathrm{CO}_{2}$ in Venues, $\mathrm{N}_{2}$ in Pluto and $\mathrm{O}_{2}$ in Mercury.

\section{References}

1. Murray CD, Dermott SF (1999) "Solar System Dynamics". Cambridge University press, UK.

2. Potter A, Morgan T (1985) "Discovery of Sodium in the Atmosphere of Mercury". Science 229: 651-653.

3. Richard R, Hodges Jr. (2000) "Distributions of hot oxygen for Venus and Mars”, Journal of Geophysical Research 105: 6971-6982.
4. Lewis JS, Prinn RG (1984) Planets and their atmospheres: Origin and evolution. Academic Press, Orlando, Florida.

5. Michael Seeds, Dana Backman (2015) Foundations of Astronomy (13thedn) Cengage Learning, Independence, KY.

6. Mizuno H (1980) Formation of the Giant Planets. Progress of Theoretical Physics 64: 2

7. Lindal GF, Wood GE, Hotz HB, Sweetnam DN (1983) The atmosphere of Titan: An analysis of the Voyager 1 radio occultation measurements. Icarus 53: 2 .

8. Lyttleton RA (1969) On the internal structures of mercury and Venus. Astrophysics and Space Science 5: 1

9. Pidwirny M (2013) Atmospheric composition. The encyclopedia of the Earth. 